IZA DP No. 6842

Electricity Prices, River Temperatures and Cooling Water Scarcity

Grant R. McDermott

Øivind A. Nilsen

September 2012 


\title{
Electricity Prices, River Temperatures and Cooling Water Scarcity
}

\author{
Grant R. McDermott \\ Norwegian School of Economics \\ Øivind A. Nilsen \\ Norwegian School of Economics \\ and IZA
}
Discussion Paper No. 6842
September 2012

\author{
IZA \\ P.O. Box 7240 \\ 53072 Bonn \\ Germany \\ Phone: +49-228-3894-0 \\ Fax: +49-228-3894-180 \\ E-mail: iza@iza.org
}

\begin{abstract}
Any opinions expressed here are those of the author(s) and not those of IZA. Research published in this series may include views on policy, but the institute itself takes no institutional policy positions.

The Institute for the Study of Labor (IZA) in Bonn is a local and virtual international research center and a place of communication between science, politics and business. IZA is an independent nonprofit organization supported by Deutsche Post Foundation. The center is associated with the University of Bonn and offers a stimulating research environment through its international network, workshops and conferences, data service, project support, research visits and doctoral program. IZA engages in (i) original and internationally competitive research in all fields of labor economics, (ii) development of policy concepts, and (iii) dissemination of research results and concepts to the interested public.
\end{abstract}

IZA Discussion Papers often represent preliminary work and are circulated to encourage discussion. Citation of such a paper should account for its provisional character. A revised version may be available directly from the author. 


\section{ABSTRACT}

\section{Electricity Prices, River Temperatures and Cooling Water Scarcity}

Thermal-based power stations rely on water for cooling purposes. These water sources may be subject to incidents of scarcity, environmental regulations and competing economic concerns. This paper analyses the effect of water scarcity and increased river temperatures on German electricity prices from 2002 to 2009. Having controlled for demand effects, the results indicate that the electricity price is significantly impacted by both a change in river temperatures and the relative abundance of river water. An implication is that future climate change will affect electricity prices not only through changes in demand, but also via increased water temperatures and scarcity.

JEL Classification: Q25, Q41, Q5, C3

Keywords: thermal-based power, water scarcity, water-energy nexus

Corresponding author:

Øivind Anti Nilsen

Department of Economics

Norwegian School of Economics

$\mathrm{N}-5045$ Bergen

Norway

E-mail: oivind.nilsen@nhh.no

\footnotetext{
* This paper has benefitted from comments and suggestions from two anonymous referees, Kjetil Andersson, Valeria di Cosmo, Gunnar Eskeland, Dan Gordon, Pål J. Nilsen, Fred Schroyen, seminar participants at the Norwegian School of Economics (NHH) and University of Bergen, as well as a Norwegian Association for Energy Economics (NAEE) meeting at NHH January 2011, the 6th Nordic Econometric Meeting in Denmark, May 2011, Bergen Economics of Energy and Environment Research (BEEER) Conference, June 2012, International Energy Workshop (IEW) June 2012, and Mannheim Energy Conference June 2012. Financial support from the CELECT project, funded by the Research Council of Norway, is gratefully acknowledged.
} 


\section{Introduction}

Thermal-based power facilities, such as nuclear and coal-fired plants, are critically dependent on water for cooling purposes. This enables them to maintain high production efficiencies, but also means that they use tremendous volumes of water every day. To give an indication of scale, the thermal industry accounts for roughly 40 percent of all freshwater withdrawals in the United States - a figure that places it alongside the agricultural sector (USDOE, 2006). Unlike agriculture, however, the majority of these withdrawals are actually returned to their natural source. Nonetheless, discharging used cooling water back into the environment presents problems of its own. The excess thermal energy absorbed by cooling water during the heat exchange will naturally cause it to warm up prior to being released back into the river or lake from which it was taken. This can ultimately raise the ambient temperature of the water source itself and cause detrimental effects to the aquatic ecosystem. Water temperatures at or above the mid-20s degree Celsius $\left({ }^{\circ} \mathrm{C}\right)$ mark are considered particularly dangerous to aqueous plants and certain fish species, since this leads to reduced oxygen levels and raised concentrations of ammoniac (Langford, 1990). As a result, many countries have enacted environmental regulations that place restrictions on the maximum allowable temperature of discharge water from power stations, otherwise known as "thermal pollution”. 1

Within this context, an emerging literature has developed that seeks to analyse how thermal-based power production might be constrained by access to water resources. Some studies largely abstract from wider climate phenomena and focus primarily on what growing energy demands means for water consumption (for instance, see Feeley et al., 2008; and

\footnotetext{
${ }^{1}$ The vulnerability to water scarcity, as well as problems related to thermal pollution, varies according to fuel type and cooling technology. For example, the low thermal efficiencies of nuclear plants make them particularly susceptible to water-related issues (for example, see: USDOE, 2006).
} 
USDOE/NETL, 2009a, 2009b, 2009c). Others have specifically tried to incorporate climate change into their analysis and even suggest adaptive strategies available to the thermal power industry in coping with a warming world. ${ }^{2}$ The Fourth Assessment Report of the Intergovernmental Panel on Climate Change (IPCC, 2007) synthesised several such studies in suggesting that future energy generation will be vulnerable to higher temperatures and a reduced availability of cooling water for thermal power stations. Citing effects from the 2003 European heat wave as a precautionary example, the report declared: "[E]lectricity production was undermined by the facts that the temperature of rivers rose, reducing the cooling efficiency of thermal power plants (conventional and nuclear) and that flows of rivers were diminished" (ibid, p. 367). Though typically local in focus, the list of individual studies covering equivalent issues includes Hurd and Harrod (2001), Arnell et al. (2005), Maulbetsch and DiFilippo (2006), Kirshen et al. (2008), Sovacool (2009), and Sovacool and Sovacool (2009).

In terms of predictive capability, Koch and Vögele (2009) offer a more adaptable framework that lends itself to scenario analysis. They do so by constructing an integrated water management model that can be used to simulate the interconnected effects of changing energy needs and water availability on thermal-based power production. This model is then applied to individual plants under various hypothetical climate and economic scenarios. However, whilst Koch and Vögele go on to comment on some broader socio-economic outcomes, they acknowledge that their simulations do not account for the fact that "water shortages affecting large regions[...] could have an impact on energy prices”. Förster and

\footnotetext{
${ }^{2}$ The links between thermal-based power production, water scarcity and climate have also received growing attention in popular media formats. This includes news stories of European power plants shutting down during heat waves of the last decade (Gentleman, 2003; Godoy, 2006; Pagnamenta, 2009) and similar problems in the US (AP, 2008; Sohn, 2011; Eaton, 2012), as well as implications of the nuclear power sector's dependency on water and recurring incidents of drought (Kanter, 2007; Dell'Amore, 2010). The linkage between power supply and water needs has also received increased attention in the wake of recent events at the Fukushima Daiichi nuclear plant in Japan (Chellaney, 2011).
} 
Lilliestam (2010) adopt a somewhat narrower approach by simulating the effects of climate change on a single large (hypothetical) nuclear plant in Central Europe that is reliant on oncethrough cooling technology. Their results indicate that annual load losses could be as high as $11.8 \%$, with annual plant losses upwards of $€ 100$ million for the worst case scenarios. In turn, Van Vliet et al. (2012) provide a more general overview of how the power sector will be affected by climate change. Their simulations show that the average summer capacity of power plants in Europe and the US will be reduced by 6.3-19 percent and 4.4-16 percent, respectively, depending on cooling system type and climate scenario for 2031-2060. They too, however, make no explicit attempts to model for an effect on electricity prices.

In contrast to the simulation-based studies named above, Linnerud et al. (2011) tread a largely empirical line. Using European data to analyse the impact that climate change may have on the nuclear industry, they find that an average temperature rise of $1^{\circ} \mathrm{C}$ reduces the supply of nuclear power by roughly half a percent. Finally, Kopytko and Perkins (2011) provide a more discursive overview of the inherent vulnerabilities that nuclear power will be exposed to as a result of climate change. Among other things, they specifically highlight cooling water scarcity as a key impediment to future investment in inland nuclear plants.

The purpose of this paper is to determine how electricity prices are impacted by access to cooling water. Indeed, despite a growing literature on the sensitivity of thermalbased power production to water-related factors, we are unaware of any studies that establish an empirical effect on the price of electricity. ${ }^{3}$ Our aim is to quantify what these effects are and, in doing so, provide fresh insight into how the power industry's dependence on cooling water yields direct economic costs.

\footnotetext{
${ }^{3}$ Boogert and Dupont (2005) suggest that water temperatures resulted in increased Dutch electricity prices (via a supply-side shock) during the 2003 heat wave. However, their concise paper does not offer any empirics beyond some descriptive statistics.
} 
We use German data in this study and this has several advantages. First, at a total consumption level of around 550 TWh in 2010, the German power market is the largest in Europe and is characterised by a diverse mix of input fuels (Kristiansen, 2011). The market is also characterized by a large number of power plants scattered around the country. That said, four companies are alone responsible for approximately 80 percent of total production capacity (Müsgens, 2006; Möst and Genoese, 2009). During the 2002-2009 review period of this paper, the country derived approximately 60 percent of its electricity needs from fossil fuels (mostly coal), 23 percent from nuclear, and the remainder from a combination of renewables. ${ }^{4}$ According to the International Energy Agency and as shown in Figure 1, these numbers very closely parallel those of the OECD region as a whole (IEA, 2011a). ${ }^{5}$ Germany is therefore a very reasonable "representative agent", from which one can make wider inferences about the impact that water scarcity has on thermal power production and, consequently, electricity prices.

[Figure 1 about here]

The second factor in support of Germany as a case study is the availability of a wide series of relevant data - including wholesale electricity data and hydrological records - which makes it an amenable choice for conducting empirical analysis. The German power market was fully liberalised in 1998 and by 2001 the major electricity trading platforms had merged to form a single entity, the Leipzig-based European Energy Exchange (EEX). With regard to

\footnotetext{
${ }^{4}$ The role of nuclear power in Germany has been highly contested over the last several decades, with renewed public interest in the wake of the stricken Fukushima Daiichi plant in Japan. Following a period of political flip-flopping on the issue, the German government in 2011 committed to phasing out nuclear power by 2022. However, we do not explicitly consider these developments in this paper, since they took place after the relevant period of study

${ }^{5}$ The relative role that thermal-based power plays is comparable even at a global level - where the contributions of fossil fuels and nuclear to total power generation in 2009 were 67 percent and 13 percent, respectively (IEA, 2011b).
} 
institutional settings, market participants on the EEX are able to trade a variety of products corresponding to different time horizons and derivative positions. A range of standardised products are also traded in the form of bilateral over-the-counter (OTC) agreements between direct counterparties, often concluded via brokerage firms.

This paper uses data on the day-ahead EEX spot auction, during which hourly electricity contracts and block contracts can be traded until midnight of the previous day. ${ }^{6}$ The EEX spot market accounts for approximately 30\% of German electricity demand, and we would expect certainly marginal changes in river levels or temperatures to be reflected in these prices. Furthermore, the spot price also acts as a reference point for all upstream market participants, regardless of where and what they are trading. If not, there would be costless arbitrage opportunities (Viehmann, 2010; Kristiansen, 2011). The day-ahead spot market should thus not only reflect the underlying long-term demand and supply conditions of the power sector, but also respond to short-term shocks. This includes power plants being entered into constrained production due restrictions on their intake of cooling water.

The third and perhaps most important reason for using German data, is that the country's electricity sector has proven vulnerable to incidences of water scarcity and compromised water quality in the past. This has been especially true during very hot periods such as the European heat waves in 2003 and 2006, when Germany joined the likes of France and Spain in suffering from significantly reduced production capacities. A proximate cause of this outcome was the fact that river temperatures began to exceed the regulatory threshold imposed on thermal water pollution. Faced with a power system already straining under the pressure of unusually high demand for cooling, German federal authorities initially provided

\footnotetext{
${ }^{6}$ Instead of using average daily prices, one might be tempted to argue that higher-frequency data (e.g. hourly) would allow for a higher degree of analytical precision. There are several reasons why we do not follow this approach. First, the supply of produced electricity is not particularly flexible for the baseload plants that we focus on in this study. Second, environmental authorities are highly unlikely to respond to changes on an hourly basis, but rather issue daily orders to power plant operators. Third, daily data is consistent with our other data (e.g. hydrological).
} 
emergency dispensation for power stations to flout environmental laws. However, they were eventually forced to uphold the standard restrictions on discharging hot water into the environment in order to protect river fauna and flora. Overall, at least 15 thermal plants had to be shut down or entered into constrained production because of water-related issues during the summer months of 2003 (Müller et al., 2007, 2008). Similarly, at least 12 plants were throttled during the 2006 heat wave so as to limit the discharge of thermal waste water into rivers.

It is against this backdrop that we can preview the key findings of this paper. Having successfully controlled for various demand-side effects, our empirical results indicate that the electricity price is significantly impacted by both a change in river temperatures and the relative abundance of river water. Falling river levels are generally associated with a higher electricity price, while prices will also be driven higher once average river temperatures breach regulatory thresholds. For instance, we estimate that an increase in average river temperatures from $25^{\circ} \mathrm{C}$ to $26^{\circ} \mathrm{C}$ will bring about a near four percent increase in electricity prices over the course of a week.

The remainder of the paper is structured as follows. Section 2 presents the theoretical framework and discusses our econometric strategy. Section 3 describes the data. Section 4 presents the empirical findings together with a discussion on alternate specifications and aggregation issues. Concluding remarks are provided in Section 5.

\section{Theoretical Model and Econometric Strategy}

Our model aims to incorporate the thermal production process - albeit in a highly stylised manner - to account for the effect that increased river temperatures have on electricity output. In brief, thermal energy can be converted into electrical energy more efficiently in the 
presence of an external coolant, such as water. ${ }^{7}$ This allows excess heat from the production cycle to be transferred to the coolant and subsequently disposed of. The cooling technology that thermal-based power plants use may be divided into two broad categories: once-through or closed-circuit systems. The former requires that far greater volumes of water be withdrawn from natural sources, while the latter "consumes” more in the form of evaporation. That said, we abstract from such differences and instead focus on the core principle that cooling is essential to maintaining efficiency levels in any thermal-based power plant - irrespective of whether it is fuelled by coal, gas or nuclear energy. We therefore assume a simple production technology of

$$
Q=A\left(T_{E W}-T\right) \cdot W
$$

In other words, the production of electricity $Q$ is contingent on the difference in temperature of the discharge water at the outlet point, $T_{E W}$, and the cooling water at the intake point, $T$. Production will increase as this temperature difference increases, i.e. $A^{\prime}>0 .{ }^{8}$ This formulation effectively takes the inner workings of the thermal engine as exogenous and instead focuses on the fact that surplus heat energy is transferred to the cooling water via a heat exchange. A higher temperature difference between the discharge water and its original source therefore implies a higher thermal efficiency (i.e. conversion of thermal energy into electrical energy). Importantly, the model also captures the possibly that thermal-based plants

\footnotetext{
${ }^{7}$ This result is famously rendered by Carnot's theorem, which holds that the efficiency of a thermalbased engine is directly proportional to the temperature differential between its high and low temperature reservoirs (e.g. Langford, 1990).

${ }^{8}$ An underlying assumption is that $T_{E W} \geq T$. In other words, there is a cooling effect due to the heat exchange that takes place in the plant condenser. The specification that we have used here is thus also indicative of the fact that the cooling effect becomes increasingly negligible as the temperature difference falls.
} 
can use more cooling water, $W$, to compensate for a low temperature differential. Figure 2 provides a stylised depiction of the production cycle used in our model.

[Figure 2 about here]

The production of electricity by thermal-based power stations is subject to the following constraint

$$
\frac{W}{S} \cdot T_{E W}+\left(\frac{S-W}{S}\right) \cdot T \leq \bar{T}
$$

This reflects the fact that environmental authorities set a cap, $\bar{T}$, on the temperature of the downstream river volume, $S$, which occurs as a result of the mixing between discharged cooling water, $W$, and the river water not used for cooling $(S-W)$. Thus, $\frac{W}{S}$ is the share of total river water used for cooling. The constraint implies that rather than undergoing a complete shutdown, the plant has the option of reducing the flow of discharge relative to the volume of downstream mixing water when the temperature of each unit of discharged water, $T_{E W}$, is relatively hot. However, as the temperature of the river water itself approaches the regulatory limit (e.g. during very hot summer months), the plant has little room for manoeuvring and will likely have to decrease output. ${ }^{9}$

\footnotetext{
${ }^{9}$ Of course, environmental authorities will also typically impose limits on the temperature of the discharged water itself - let us say $\bar{T}_{E W}$ - and/or on the temperature differential between river water at the intake point and the discharge (c.f. Mimler et al, 2009). In the interests of parsimony, however, we ignore these additional limits in our model. Indeed, one could argue that including a constraint, $\bar{T}$, on the temperature of the downstream river volume, $S$, already serves to capture these effects indirectly.
} 
The strategic decision variable available to power plants in our theoretical framework is quantity. It should be noted that electricity is a homogeneous product that cannot be stored, and demand must be perfectly balanced by supply at all times. Given the institutional settings of the German power market, our model allows for potential market power, but is also generalizable to a situation where the representative power plant behaves as a price-taker. We therefore model the profit, $\pi$, for thermal-based plants as follows

$$
\pi=p(Q+F) Q-c(Q)-p_{w}(R L) \cdot W
$$

where $p($.$) denotes the inverse demand function and total electricity demand is the sum of$ power produced by the analysed plants, $Q$, together with electricity imports and the other sources that aren't dependent on cooling water (e.g. wind power), $F$. The cost function, $c(Q)$, captures the marginal costs associated with the production of additional quantities of electricity. In addition to these standard production costs, the latter part of the expression, $p_{w}(R L) \cdot W$, reflects the fact that there are costs associated with drawing cooling water, $W$, from the external coolant (here: river). These are said to be a function of the river level, $R L$, such that $p_{w}{ }^{\prime}<0$.

By substituting in the technology function for the water parameter, $W$, we have the following profit maximisation problem

$$
\pi=p(Q+F) Q-c(Q)-p_{w}(R L) \cdot \frac{Q}{A\left(T_{E W}-T\right)}
$$

s.t.

$$
\frac{Q}{S \cdot A\left(T_{E W}-T\right)} \cdot T_{E W}+\left(1-\frac{Q}{S \cdot A\left(T_{E W}-T\right)}\right) \cdot T \leq \bar{T}
$$


Taking the first-order condition with respect to $Q$ yields

$$
p^{*}\left(1-\frac{1}{\varepsilon}\right)=\frac{\partial c\left(Q^{*}\right)}{\partial Q}+p_{w}(R L) \cdot \frac{1}{A\left(T_{E W}-T\right)}+\lambda \cdot \frac{1}{S \cdot A\left(T_{E W}-T\right)} \cdot\left(T_{E W}-T\right)
$$

where $Q^{*}$ is the optimal level of produced energy (with corresponding optimal price, $p^{*}$ ), $\lambda$ is the shadow price of the constraint, and $\varepsilon$ denotes the price elasticity where we have integrated out the demand effects for electricity provided by the other sources. ${ }^{10}$

Given that $p_{w}{ }^{\prime}<0$, a lower river level will effectively have the same impact as an increase in production costs. Falling river levels will consequently reduce the supply of electricity and ultimately bring about an increase in price, i.e. $\frac{\partial p^{*}}{\partial R L}<0$. The effect of river temperatures is slightly more complex as it will impact price through various channels. First, an increase in $T$ will negatively impact the thermal efficiency of a plant. This effect could be mitigated by withdrawing more cooling water, $W$, although this will bring with it its own costs, since profit is a function of $p_{w}(R L) \cdot W$. Moreover, when the constraint is binding $(\lambda>0)$, the only way that a power plant can respond to increased river temperatures when it is up against the regulatory threshold will be to reduce $W$ and therefore lower the production. In either case, an increase in $T$ will reduce the quantity of electricity by shifting the supply curve to the left. This in turn will lead to an increase in price, i.e. $\frac{\partial p^{*}}{\partial T}>0 .^{11}$

As a matter of convenience, we do not model the market behaviour of power plants explicitly in our regression analysis. Instead we focus on a reduced-form system of demand

\footnotetext{
${ }^{10}$ This means that the model encompasses settings where the representative plant is a price-taker (i.e. $\varepsilon \rightarrow-\infty)$, or where it exercises market power. Of course, a plant's ability to react to changes in demand or marginal costs will also depend on what fuel type they are. For instance, nuclear power plants are built for providing a constant baseload, while gas-fired plants are more flexible.

${ }^{11}$ Please see the appendix for a more detailed derivation of the comparative statics.
} 
and supply equations, where electricity prices and quantities are jointly determined in a market-clearing equilibrium. The system of supply and demand equations that form the basis for our regression model is represented by equations (6) and (7), respectively.

$$
\begin{aligned}
& \ln P_{t}=\beta_{0}+\beta_{1} \ln Q_{t}+\beta_{2} \ln \text { RiverLevel }+\beta_{3} \ln \text { RiverTemp }_{t}+\beta_{4} \ln F_{t}+\beta_{T}{ }^{\prime} \mathbf{T}_{t}+v_{t} \\
& \ln Q_{t}=\alpha_{0}+\alpha_{1} \ln P_{t}+\alpha_{2} \ln H D D_{t}+\alpha_{3} \ln C D D_{t}+\alpha_{4} \ln N W D_{t}+\alpha_{T}{ }^{\prime} \mathbf{T}_{t}+u_{t}
\end{aligned}
$$

where
$P \quad$ - Daily clearing price for electricity
Q $\quad$ - Daily electricity consumption
RiverLevel - The aggregated river level
RiverTemp - River Temperature
$F \quad$ - Fuel (input) costs
HDD - Heating degree-day (degrees below $18^{\circ} \mathrm{C}$ outside air)
$\mathrm{CDD} \quad$ - Cooling degree-day (degrees above $22^{\circ} \mathrm{C}$ outside air)
NWD - Non-working days (i.e. either a weekend or public holiday) (0/1)
$\mathrm{T} \quad$ - A set of seasonal and trend variables

We are primarily interested in the supply equation (6), since this captures how production is effected by access to cooling water. The supply of electricity is defined here by its price $(P)$, which is then a function of quantity $(Q)$ and several supply-related variables. The supply-side regressors of greatest interest to this study are river levels (RiverLevel) and river temperatures (RiverTemp). These two coefficients should reflect how electricity supply is constrained by diminished cooling water availability, due to either relative scarcity (i.e. falling river levels) or regulatory concerns (i.e. river temperatures breaching environmentally sensitive thresholds). The supply equation also includes the cost of input fuels, while a group of month and year dummies account for seasonality and trend.

The demand equation (7) includes two terms that capture the nonlinear effect of changing temperatures on electricity demand: Heating degree day (HDD) and cooling degree day $(C D D)$ capture the extent to which air temperatures fall outside a given "comfort zone”, 
which we define as $18^{\circ} \mathrm{C}-22^{\circ} \mathrm{C} .{ }^{12}$ An $H D D$ measures how far the temperature drops below $18^{\circ} \mathrm{C}$ on any given "cold" day (thus requiring heating), while a $C D D$ measures how much the temperature exceeds $22^{\circ} \mathrm{C}$ on any given "hot" day (thus requiring cooling). These two variables thus allow our demand function to respond to the discomfort presented by both cold and warm weather. ${ }^{13}$ The dummy variable $N W D$ is included to reflect the fact that electricity demand typically falls on non-working days, such as weekends and public holidays. As with the supply equation, month and year dummies are included to account for seasonal variations and trend in demand.

It is important to note that $P$ and $Q$ are jointly determined within the above system of equations. The simultaneity of supply and demand means that simply regressing electricity prices on volumes using ordinary least squares (OLS) would generate inconsistent parameter estimates. To resolve this issue we adopt an instrumental variable (IV) approach to properly identify causal effects within a two-stage least squares (2SLS) regression framework. We can see from the order condition that both equations (6) and (7) are overidentified. That said, we primarily interested in the former (i.e. supply equation), for which we have to instrument for $Q$. The critical assumption here is that our chosen instrumental variables - CDD, HDD and NWD - pass the exclusion restrictions requirement. That is, they do not impact prices directly, but instead only indirectly through changes in demand. The temperature discomfort associated with $C D D$ and $H D D$ is thus assumed to cause an increase in demand but have no bearing on direct supply. Since we control for changing river levels and river temperatures separately, this seems a valid assumption. Similarly, the supply of electricity is not expected to be materially constrained by the fact that it is a weekday or public holiday, while demand

\footnotetext{
${ }^{12}$ This is a fairly standard range in the literature. Some studies (c.f. Bessec and Fouquau, 2008) contend that the turning point for temperate European countries occurs at slightly low intervals, from roughly $16^{\circ} \mathrm{C}$. Having tested this formally, however, there is no significant difference in using $16^{\circ} \mathrm{C}$ or $18^{\circ} \mathrm{C}$ as the threshold for $H D D$ s for our data set.

${ }^{13}$ To illustrate, an aggregate daily temperature of $17^{\circ} \mathrm{C}$ would correspond to one $H D D$, while a temperature of $15^{\circ} \mathrm{C}$ would equate to three $H D D s$. Similarly, a temperature of $27^{\circ} \mathrm{C}$ would correspond to five $C D D$ s, and so forth.
} 
will respond to the drop in economic activity. To be sure of the exogeneity of the instruments, we also conduct the Sargan-Hansen overidentification test. Furthermore the standard Hausman specification test is used to test for endogeneity, while the Anderson identification test will check the validity of our instruments. ${ }^{14}$

\section{Data Description}

The data for this paper are collected from several different sources. The data for each series consist of daily values over the period 2002 to 2009. Data on German spot electricity prices and volumes are obtained from the aforementioned European Energy Exchange AG (EEX). Daily electricity data are available for both base (24-hour continuous) and peak (12 hours from 8am to 8pm) periods. However, we focus exclusively on the base series in this paper. The primary reason for this is the fact that the power plants most vulnerable to water-related factors - such as nuclear and coal-fired plants - are all baseload electricity operators. Consequently, one would expect that the impact of any supply constraints to these plants will already be visible within the base price. Moreover, having a data point that runs over an entire day helps to ensure consistency with the other variables, which also cover daily time steps. It should also be noted that electricity prices in Germany are geographically uniform with no zonal differentiation. ${ }^{15}$ Both electricity prices and volumes are log-transformed for the regression analysis.

Air temperature data are obtained from Deutscher Wetterdienst (German Meteorological Service). To compute aggregate temperature data, daily values are first collected for each capital city of the 16 German federal states. In the minority of cases where

\footnotetext{
${ }^{14}$ See Baum et al. 2007.

${ }^{15}$ The regulatory framework of the EEX does allow for the market to be broken up into different price zones when grid capacities are unable to fully execute the spot auction schedules, but this was not necessary during the review period of this study (Ockenfels et al., 2008)..
} 
data limitations mean that a state cannot be represented by its capital, a significant counterpart city is used instead. ${ }^{16}$ The mean temperature recording in all of these cities (computed from 24 hourly observations) is then computed into a single daily mean temperature series for the entire country. This aggregating step is taken to ensure consistency with the uniform electricity prices across the German states. Next, we create a set of degree day interaction dummies, $H D D$ and $C D D$. These variables are adjusted so as to reflect logged values, i.e. $D^{\text {temp }>22^{\circ}} \cdot \log \left(t e m p-22^{\circ}\right)$, and $D^{\text {temp }<18^{\circ}} \cdot \log \left(18^{\circ}-t e m p\right)$. The daily mean air temperature series is shown in Figure 3 together with the designated comfort zone.

[Figure 3 about here]

Hydrological data, in the form of river levels and temperatures, are provided by the Bundesanstalt für Gewässerkunde (Federal Institute of Hydrology). Data measurements were taken from gauging stations situated at various points along four major German rivers - the Elbe, Main, Neckar, and Rhine. It is worth noting that these rivers acted as the water source for a number of nuclear plants during the 2003-2009 review period, in addition to several coal-fired plants that also suffered reduced capacity due to restrictions on thermal pollution. ${ }^{17}$ Our dataset should therefore be able to capture the relevant effects of cooling water scarcity and environmental regulation. To help ensure consistency with our other data, we take the daily averages for each individual river and then use these to construct two series of mean values for the whole country: River Level $(\mathrm{cm})$ and River Temperature $\left({ }^{\circ} \mathrm{C}\right)$.

\footnotetext{
${ }^{16}$ For instance, data for Wiesbaden, the capital of Hesse, were not available so these were substituted with data from the much bigger Frankfurt.

${ }^{17}$ The list of nuclear plants includes the Biblis and Phillipsburg (Rhine), Brunsbüttel and Krümmel (Elbe), Grafenrheinfeld (Main), and Neckarwestheim and Obrigheim (Neckar). The Obrigheim Plant was decommissioned in 2005, but was among those temporarily switched off during the 2003 heat wave due to thermal pollution.
} 
Apart from being log-transformed, data from the River Level series are entered directly into the regression model. However, we make two adjustments to the River Temperature series to better capture how regulation of thermal pollution impacts electricity prices. The first is to generate a standard dummy variable that tests for a difference in price intercept when river temperatures exceed a defined regulatory limit of $25^{\circ} \mathrm{C}$. The second is to specifically measure the continued rise in temperature above this $25^{\circ} \mathrm{C}$ threshold, i.e. $D^{\text {RivTemp }>25^{\circ}} \cdot \log \left(\operatorname{RivTemp}-25^{\circ}\right)$. This formulation is aimed at ensuring some flexibility and allows for a non-linear temperature effect around the regulatory threshold. It should be noted that our specification here is consistent with the theoretical model described in Section 2; a shadow price comes into play when the river temperature is greater than some regulatory limit, with a positive marginal effect on electricity prices as temperatures increase above that threshold. Figure 4 depicts this relationship in a stylised manner.

[Figure 4 about here]

We use the log-transformed, 90-day moving average (MA) of Brent crude oil to account for the effect that changing fuel (i.e. input) costs have on power production. These are obtained from Bloomberg and adjusted for changes to the USD-EUR exchange rate. While oil-fired plants do not play a substantial role in the German electricity market, oil is widely used as a proxy for natural gas and it is even used within the power industry to forecast the general price movements of coal. The fact that daily spot prices are available for oil also makes it more amenable to our empirical analysis.

Finally, we include a number of parameters in the model to control for trend and seasonality. Month and year dummies are created to pick up the standard seasonal characteristics found in electricity data, as well as unaccounted trends in demand. (For 
example, those stemming from changes in consumers' aggregate income level over the review period.) Furthermore, since electricity consumption is expected to be highly correlated with economic activity, a dummy variable for non-working days (i.e. weekends and public holidays) is also included in the regression analysis.

\section{Empirical Results}

Our primary estimation results are presented in Table 1. Model (1) is characterised by a static setting that utilises only contemporaneous variables. Models (2) and (3) are dynamic in the sense that they include lagged electricity price and volume observations as additional regressors. All results have been calculated using heteroskedasticity- and autocorrelationconsistent (HAC) estimators (Newey and West 1987).

[Table 1 “Primary models” about here]

Considering model (1) first, the rationale underpinning this "static" specification is that - given its role as an optimising market - the spot power exchange should effectively constitute a new market each day. The coefficient on volume (5.976) suggests that a one percent increase in the volume of consumed electricity will induce a six percent increase in the base electricity price. This implies that the daily power supply in Germany is highly inelastic, which we would expect given the very short-term nature of the data used in this study (i.e. daily observations).

Water scarcity, as measured by changes to the average river level, returns a negative coefficient in the static model (-1.025); indicating that the electricity price is expected to fall by around one percent for every one percent rise in river levels. This is consistent with our 
earlier hypothesis that electricity prices move in the opposite direction to the availability of cooling water, even after controlling for potential demand effects.

Model (1) also shows that there is a positive, statistically significant relationship between the electricity price and an aggregate river temperature over $25^{\circ} \mathrm{C}$. Once this threshold is breached, the price rises by 0.277 percent with every additional percentage increase in river temperatures. To put this in perspective, a rise in average river temperatures from $25^{\circ} \mathrm{C}$ to $26^{\circ} \mathrm{C}$ would yield an approximate 1.2 percent increase in the price of electricity. The fact that the $D^{\text {Riv.Temp }>25^{\circ} \mathrm{C}}$ dummy returns a statistically insignificant coefficient implies that there is no discontinuity around this $25^{\circ} \mathrm{C}$ threshold. Again, this is consistent with our theoretical model in which, rather than simply shutting down, power plants have the option of reducing power to stay within the regulatory limits set by authorities.

While fuel costs are not of special interest to this paper, the coefficient on the 90-day MA for Brent crude is positive and statistically significant. The electricity price is shown to rise by half a percent for every percent increase in the price of oil. This is not unsurprising given that fossil fuels serve as an important factor of production in generating electricity. The set of month and year dummies are not reported on an individual basis, but they are all jointly significant. $^{18}$

Our use of an IV/2SLS approach has been motivated by the fact that prices and quantities are determined simultaneously. This is confirmed by the Durbin-Wu-Hausman test, which shows that endogeneity is a problem and that OLS should be discarded in favour of 2SLS. Further, Anderson's canonical correlation test shows that the instruments themselves $H D D, C D D$ and $N W D$ - are relevant, while the Hansen's $J$ test of overidentifying restrictions shows that they are also valid.

18 There is an increasingly negative coefficient on the year dummy coefficients until 2009, demonstrating that electricity prices have been increasing slowly relative to volumes over the years. Furthermore, the coefficients on the month dummies indicate that German electricity prices are typically higher in the summer months. 
Applying an augmented Dickey-Fuller test (ADF) on the residuals for model (1) shows that persistency in the data does not appear to be a problem. ${ }^{19}$ However, further testing does reveal the presence of positive autocorrelation. A probable explanation for this is misspecified dynamics - in particular, our reliance thus far on a completely static model specification. Yet it could be argued that today's electricity price is correlated with the previous day's price, or even that of the week before. This idea is given credence by the fact that electricity supply is comprised of quasi-fixed proportions of baseload and variable power. Baseload facilities such as nuclear and coal-fired power plants are typically constrained in their ability to change output levels. ${ }^{20}$ One might therefore argue that there is some "memory" in the power market system and that our modelling efforts could be improved by incorporating dynamic aspects.

The key results from two such dynamic models, which include one- and seven-day lags for both electricity price and volumes, are presented in the second and third columns of Table 1. These lags are chosen to account for the inertia from the previous day and weekday effects. Model (2) is a straightforward extension of our static model, while in model (3) we want to open up for the possibility that changes in water availability matter at different stages of relative abundance. Thus, the continuous river level series has been replaced by spline partitions. Since the majority of the coefficients of these two models are qualitatively indistinguishable, we consider them together.

It can immediately be seen that the coefficients on the lagged endogenous variables in both dynamic models are all statistically significant. This goes some way towards vindicating

\footnotetext{
${ }^{19}$ Although not reported, it is also tested whether persistency (i.e. non-stationarity) is a problem for the log-transformed electricity prices- and volumes using an ADF test. Having accounted for trends in the form of year and monthly dummies we are able to reject the null hypothesis of non-stationarity for these series.

${ }^{20}$ The load-following capacity of baseload power is an important concept here. In particular, nuclear and coal-fired plants are normally run continuously at more-or-less constant level of output. This is both a matter of economic efficiency (since they have low variable costs in comparison with the high fixed costs that must be recouped), and technical efficiency (since these plants cannot readily alter power output in the same way that gas or hydro plants can). See, for instance, WNA (2011).
} 
our suspicions that the German electricity spot exchange does not simply constitute a "new" market every day. Illustrating by way of model (2), the coefficient on the contemporaneous volume of electricity (i.e. 8.267) denotes the short-run, instantaneous impact of a change in quantity on price. The corresponding long-run multiplier is found by incorporating the lagged endogenous variables of our model and can be calculated as [(8.267-3.729-2.28)/(1-0.6240.138)=] 9.487. Testing this figure reveals it to be statistically significant at the one percent level. The dynamic model specification therefore predicts that a one percent increase in electricity volumes will lead to a 9.5 percent increase in price over the course of a full week. Again, this describes a very inelastic supply curve, but it is representative of the inertia present within the power system.

Looking next at the effect of river temperatures, both dynamic models show that there is a positive impact on electricity prices once the $25^{\circ} \mathrm{C}$ threshold is breached. A one percent increase in river temperatures above this mark will yield an increase in contemporaneous prices slightly greater than 0.2 percent. The equivalent long-run effect is closer to 0.9 percent. Thus, a temperature rise from $25^{\circ} \mathrm{C}$ to $26^{\circ} \mathrm{C}$ would bring about an immediate price increase of approximately 0.9 percent, or equivalently, an increase of 3.8 percent over the next seven days. Once more, these effects are all statistically significant at the one percent level.

The key distinction between our two dynamic models lies in the way that they measure the impact of changing river levels. Model (2) is a straightforward extension of model (1) in that it uses a single, continuous series. Like its static counterpart, model (2) suggests a negative relationship with the electricity price: A one percent drop in river levels is associated with a 0.4 percent rise in the concurrent electricity price, while the relevant longrun multiplier suggests an approximate 1.6 percent rise over the course of a week.

For model (3), we split the river level series into three splines of equal size based on percentile distribution: i) “Low” (0\%-33\%); ii) “medium” (33\%-67\%); and iii) "high” (67\%- 
$100 \%) .{ }^{21}$ Only changes within the "high" river level category are shown to be statistically significant: A one percent drop in river levels within this range will lead to a 0.6 percent rise in contemporaneous prices, or a 1.8 percent rise in the long run. A potential explanation for the insignificance of the "medium" and "low" river level splines could be that those plants most reliant on water consumption - i.e. those most sensitive to water scarcity - have already been forced to power down by the time that rivers reach their lowest levels. Regardless, formal testing reveals that the coefficient on the "mid" spline is statistically indistinguishable from that of the "high" spline ( $p$-value of 0.31). Conducting a similar test on the "low" spline coefficient reveals that it too is statistically identical to the "high" spline ( $p$-value of 0.18 ). As a consequence of these tests, it makes sense to do away with the separate splines and simply include river levels as a single continuous series as in our preferred specification, model (2).

Running through the same set of statistical tests described previously, we are able to confirm the validity of our instruments (as well as the presence of endogeneity that necessitates the use of an IV approach in the first place). A more pertinent question concerning the extension towards a dynamic specification, however, is whether it removes the autocorrelation that was present in the contemporaneous models. And, indeed, testing the predicted residuals now reveals that autocorrelation is substantially diminished. This adds further credibility to the notion that the dynamic specification of our model is preferable to its static counterpart. $^{22}$

In addition to the primary models presented in Table 1, we have run a number of alternate specifications and supplementary regressions to confirm the robustness of our

\footnotetext{
${ }^{21}$ Admittedly, these splines are chosen somewhat arbitrarily. However, having experimented with different cut-off points, our conclusion is that the main results are robust to such changes.

${ }^{22}$ While of lesser importance to this study, we also note that the coefficient on fuel costs is no longer significant under the dynamic specification. It would thus appear that accounting for lagged values of prices and volumes renders the variation in fuel costs insignificant in terms of being able to explain daily electricity price fluctuations.
} 
findings. ${ }^{23}$ First, instead of using month dummies, we have also tried to control for seasonal effects by incorporating a trigonometric wave function in the models. ${ }^{24}$ Doing so does not change our results in any material way. Second, we have replaced the splines of model (3) with a set of dummies that similarly divides the river level series into equal thirds ("low", "middle" and "high") based on the overall distribution. Rather than measuring the potential difference in slope coefficients, the aim here is to assess whether there are any statistically significant differences in the intercepts of the different river level groups. Again, we find that electricity prices will be driven higher as river levels fall. Third, we have included a logtransformed, 90-day $\mathrm{MA}$ of $\mathrm{CO}_{2}$ future contracts in our preferred dynamic setting. This variable is meant to act as a proxy for the input costs for substitutes of thermal-based electricity production. While we only have available data for the period 2006-2009, the basic results of our regression analysis are not altered by the inclusion of these emission permits. ${ }^{25}$

By focusing on high river temperatures (i.e. $25^{\circ} \mathrm{C}$ and above), our goal has been to capture the impact that regulatory constraints have had on power supply. One might also argue that these effects could be measured directly by looking at the specific dates when power plants were forced to enter into constrained production. Unfortunately, such specific information on regulatory interventions is hard to come by. That said, we are able to use somewhat detailed material provided by Müller et al. (2007) on shutdown dates over the period 19-31 July $2006 .{ }^{26}$ Given the limited nature of these data, we are hesitant to include them in a formal regression framework. However, when we look at how prices during these

\footnotetext{
${ }^{23}$ While none of the results from the alternate specifications are reported here, they are available from the authors upon request.

${ }^{24}$ The formulas used are $F(t)=\sin (2 . \pi . t / 365)$ and $G(t)=\cos (2 . \pi \cdot t / 365)$, respectively, where $t$ denotes time in days. This reflects the fact that a full seasonal cycle would complete once a year.

25 When we compare the results of this specification with one for the same period (2006-2009) without the additional $\mathrm{CO}_{2}$ variable, we find no difference in most of the coefficients. More importantly, the coefficient of the $\mathrm{CO}_{2}$ permit variable has a $p$-value of 0.07 . Thus, our model (2) specification is also robust to the inclusion of emission permits.

${ }^{26}$ These authors provide a rather rough estimate for the corresponding capacity loss of " 1,400 to at least 2,174 Megawatts”.
} 
marked dates compare with those immediately preceding and/or following them, a jump in prices during the period of regulatory enforcement is clearly evident, as is the return to normality once the intervention period has passed. Furthermore, there is an uncanny overlap between these days and times where the average river temperature exceeds the $25^{\circ} \mathrm{C}$ mark. If nothing else, we view this as supporting evidence in favour of our river temperature series, as well our defined regulatory threshold of $25^{\circ} \mathrm{C} .^{27}$

So far, we have followed an aggregated approach with regards to both river level and river temperature. This decision has primarily been motivated by the fact that Germany has a single electricity price common to all regions. Moreover, the purpose of this paper is to essentially test for systematic risks - particularly with regards to river temperatures and the regulation of thermal pollution. However, it could still be asked whether the individual rivers in our dataset are similar enough to warrant this type of aggregation. We have therefore subjected our data to several robustness checks. First, we construct a simple correlation matrix of the (detrended) individual river temperature series. ${ }^{28}$ These correlation coefficients fall within the interval $[0.80,0.94]$ and are highly significant. We have also looked at the share of individual temperature observations that coincide with the days that our average river temperature series breaches the $25^{\circ} \mathrm{C}$ threshold. The likelihood of an individual river exceeding $25^{\circ} \mathrm{C}$ given that the average series does, is very high $(=0.993)$. These exercises illustrate the close correspondence between the individual temperature trends and the aggregated measure of critical river temperature that we have constructed.

The correlation coefficients for the individual river levels are less pronounced, but are still highly significant. To provide a more formal test of the disaggregated river level effects

\footnotetext{
${ }^{27}$ The aggregate $25^{\circ} \mathrm{C}$ threshold that we have defined here does gloss over some river- and sitespecific issues. The permitted mixing temperature measured downstream from the thermal discharge in Germany varies between $23^{\circ} \mathrm{C}$ and $28^{\circ} \mathrm{C}$, depending on river-specific ecological characteristics (Müller et al., 2007). Having a single kink in the functional form might mask these differences. However, our choice of $25^{\circ} \mathrm{C}$ is not simply arbitrary and is instead based on a careful reading of the literature, as well as some initial testing of different thresholds.

${ }^{28}$ These series are detrended using the set of month and year dummies.
} 
though, we incorporate data from each of the individual rivers separately into the regression analysis. More precisely, we run four new regressions based on the specifications of model (2) - each time replacing the average river level series with data from a single river. These results are presented in Table 2. As can be seen from the table, the individual river level coefficients are all negative and thus indicative of a higher electricity price when river levels fall. That is not to say that they all have the same marginal impact, although this is perhaps not surprising given that the importance of these rivers in terms of providing cooling water to Germany’s thermal industry can vary quite substantially. ${ }^{29}$

[Table 2 “Individual river levels” about here]

In sum, we believe that these results serve to emphasis the validity of our predominantly aggregate approach. Again, the purpose of this paper is to test for systematic vulnerabilities and we would argue that focusing too much on individual trends and measurements actually distracts from the wider climate and its associated risks. The real danger implicit in climate change, for example, is that mean values are pushed closer to their regulatory thresholds, such that widespread capacity reductions become more commonplace. It therefore seems most appropriate to focus on the "average" effect, since this captures the systemic risk that comes when rivers all across the country are breeching their regulatory thresholds at the same time.

${ }^{29}$ As expected, the other coefficients are extremely similar across the four different models. 


\section{Concluding remarks}

This paper has sought to quantify how electricity prices are impacted by the availability of cooling water. Our analysis is primarily motivated by the fact that water plays a critical in the thermal production cycle, where tremendous volumes of freshwater are drawn every day to serve the cooling needs of thermal-based power plants around the world. At the same time, these water sources are subject to environmental regulations, competing economic concerns and periods of relative scarcity.

We have argued that Germany serves as a good case study to investigate these issues, and have based our analysis on daily data taken over a period of seven years. Having successfully controlled for various demand effects within a simultaneous equation framework, our results indicate that electricity prices are significantly affected by both falling river levels and higher river temperatures. The magnitude of these relationships varies according to the exact specifications of the regression model at hand and we have explored several contemporaneous and dynamic settings. Qualitatively, however, they all tell a very similar story: electricity prices are driven higher by falling river levels and high river temperatures. Under a fully contemporaneous setting, the electricity price is expected to rise by around one percent for every one percent that river levels fall. The dynamic specification, on the other hand, suggests that the price will rise at about half that rate in the short-run, before increasing to approximately one and a half percent in the long-run. With regards to river temperatures, the models imply that the price of electricity will increase by roughly one percent for every degree that temperatures rise above a $25^{\circ} \mathrm{C}$ threshold. Incorporating the longer-run effects implied by a dynamic model shows that prices will rise by nearly four percent over the course of a week. In addition to this slope effect, we test for a price discontinuity on either side of this $25^{\circ} \mathrm{C}$ threshold. However, we do not find evidence of a 
marked price jump once the threshold is breached. An explanation, which is consistent with our theoretical model and the surveyed literature, is that power plants reduce their output in stages rather than simply shutting down. This allows them some additional scope for managing thermal pollution, although a decrease in output - and hence increase in price cannot be fully avoided.

One implication of our findings is that future climate change will impact electricity prices not only through changes in demand, but also as a result of increased cooling water scarcity. We believe that this type of analysis would lend itself to applications in a number of regions and countries - all of which are marked by a marked dependency on thermal-based power, at the same time as being prone to drought and period heat waves. 


\section{References}

AP (Associated Press), 23 January 2008. Drought could shut down nuclear power plants. AP, Lake Norman, North Carolina. Available: http://www.msnbc.msn.com/id/22804065/ns/weather/t/drought-could-shut-down-nuclearpower-plants/ (11 November 2010).

Arnell, N., Tompkins, E., Adger, N., and Delaney, K., 2005. Vulnerability to Abrupt Climate Change in Europe, ESRC/ Tyndall Centre Technical Report No 20, Tyndall Centre for Climate Change Research, University of East Anglia, Norwich.

Baum, C. F., M.E. Schaffer, and S. Stillman. 2007. Enhanced routines for instrumental variables/generalized method of moments estimation and testing. The Stata Journal Volume 7, Number 4, pp. 465-50.

Bessec, M. and J. Fouquau. 2008. The non-linear link between electricity consumption and temperature in Europe: A threshold panel approach. Energy Economics 30 (5), 2705-2721.

Boogerta, A. and D. Dupont. 2005. The nature of supply side effects on electricity prices: The impact of water temperature. Economic Letters. Volume 88, Issue 1, July 2005, Pages 121-125.

Chellaney, B. 14 March 2011. Japan's Nuclear Morality Tale. Project Syndicate. Available: http://www.project-syndicate.org/commentary/chellaney15/English (14 March 2011).

Dell'Amore, C. 26 February 2010. Nuclear Reactors, Dams at Risk Due to Global Warming. National Geographic News. Available: http://news.nationalgeographic.com/news/2010/02/100226-water-energy-climate-changedams-nuclear/ (27 July 2011).

Dixit, A, 1976. Optimization in economic theory, $\left(2^{\text {nd }}\right.$ edition $)$, Oxford University Press.

Eaton, J. 17 August 2012. Record Heat, Drought Pose Problems for U.S. Electric Power. National Geographic News. Available: http://news.nationalgeographic.com/news/energy/2012/08/120817-record-heat-droughtpose-problems-for-electric-power-grid/ (20 August 2012).

Feeley, T.J., T.J. Skone, G.J. Stiegel, A. McNemar, M. Nemeth, B. Schimmoller, J.T. Murphy, and L. Manfredo. 2008. Water: a critical resource in the thermoelectric power industry. Energy 33, 1-11.

Förster H. and J. Lilliestam. 2010. Modeling thermoelectric power generation in view of climate change. Regional Environmental Change 10 (4), 327-338.

Gentleman, A. 13 August 2003. France faces nuclear power crisis. The Guardian, Paris. Available: http://www.guardian.co.uk/news/2003/aug/13/france.internationalnews (8 April 2010). 
Godoy, J. 26 July 2006. European Heat Wave Shows Limits of Nuclear Energy. One World, Paris. Available: http://us.oneworld.net/article/european-heat-wave-shows-limits-nuclearenergy (27 July 2010).

Hurd, B. and M. Harrod. 2001. Water Resources: economic analysis. In: Global Warming and the American Economy [Mendelsohn, R. (ed.)]. Edward Elgar Publishing Ltd, Cheltenham, pp. 106-131.

IEA (International Energy Agency). 2011a. Energy Balances of OECD Countries 2011. OECD Publishing. DOI: 10.1787/energy_bal_oecd-2011-en.

IEA. 2011b. World Energy Outlook 2011. OECD Publishing. DOI: 10.1787/weo-2011-en.

IPCC (Intergovernmental Panel on Climate Change). 2007. Climate Change 2007: Impacts, Adaptation and Vulnerability. Contribution of Working Group II to the Fourth Assessment Report of the Intergovernmental Panel on Climate Change [Parry, M.L., Canziani, O.F., Palutikof, J.P., Van der Linden, P.J., and Hanson, C.E. (eds.)]. Cambridge University Press, Cambridge, United Kingdom and New York, NY, USA.

Kanter, J. 20 May 2007. Climate change puts nuclear energy into hot water. New York Times, Paris. Available: http://www.nytimes.com/2007/05/20/health/20ihtnuke.1.5788480.html?_r=1 (27 July 2010).

Kirshen, P., M. Ruth, and W, Anderson. 2008. Interdependencies of urban climate change impacts and adaptation strategies: a case study of Metropolitan Boston USA. Climatic Change 86, 105-122.

Koch, H. and S. Vögele. 2009. Dynamic modelling of water demand, water availability and adaptation strategies for power plants to global change. Ecological Economics 68 (7), 2031-2039.

Kopytko, N. and J. Perkins. 2011. Climate change, nuclear power, and the adaptationmitigation dilemma. Energy Policy 39 (2011) 318-333.

Kristiansen, T. 2011. Power Trading Analytics and Forecasting in Germany. The Electricity Journal 24(8), pp.41-55.

Langford, T.E.L. 1990. Ecological effects of thermal discharges. Elsevier Applied Science, London.

Linnerud, K., T.B. Mideksa, and G.S Eskeland. 2011. The impact of climate change on nuclear power supply. Energy Journal 32 (1): 149-168.

Maulbetsch, J.S. and M.N. DiFilippo. 2006. Cost and value of water use at combined cycle power plants. California Energy Commission, PIER Energy-Related Environmental Research, CEC-500-2006-034.

Mimler, S., U. Müller, S. Greis, B. Rothstein. 2009. Impacts of Climate Change on Electricity Generation and Consumption. In: Leal Filho, W. (ed.): Interdisciplinary Aspects of Climate Change. Peter Lang Scientific Publishers. Frankfurt. 11-37. 
Möst, D. and M. Genoese. 2009. Market power in the German wholesale electricity market, The Journal of Energy Markets 2(2), 47-74.

Müller, U., S. Greis, and B. Rothstein. 2007. Impacts on Water Temperatures of Selected German Rivers and on Electricity Production of Thermal Power Plants due to Climate Change. In: Heneka, P., B. Zum Kley, G. Tetzlaff, F. Wenzel. (eds.): 8. Forum DKKV/CEDIM: Disaster Reduction in a Changing Climate, Karlsruhe, Germany.

Müller, U., S. Greis, and B. Rothstein. 2008. Möglicher Einfluss des Klimawandels auf Flusswassertemperaturen und Elektrizitätserzeugung thermischer Kraftwerke. Poster presented at Tag der Hydrologie 2008 (27.03.2008 - 28.03.2008), Hannover. Available: http://www.iww.uni-hannover.de/tdh2008/Poster/Mueller.pdf.

Müsgens, F, 2006, Quantifying market power in the German wholesale electricity market using a dynamic multi-regional dispatch model, The Journal of Industrial Economics 54(4), 471-498.

Newey, W. K., and K.D. West. 1987. A simple, positive semi-definite, heteroskedasticity and autocorrelation consistent covariance matrix. Econometrica 55: 703-708.

Ockenfels, A., Grimm, V., and Zoettl, G. 2008. The Pricing Mechanism of the Day Ahead Electricity Spot Market Auction on the EEX. Available: http://cdn.eex.com/document/38615/gutachten_eex_ockenfels_e.pdf.

Pagnamenta, R. 3 July 2009. France imports UK electricity as plants shut. The Times, London.

Available: http://business.timesonline.co.uk/tol/business/industry_sectors/utilities/article6626811.ece (27 July 2010).

Sohn, P. 4 August 2011. River temperature forces nuclear plant to 50 percent power. Times Free Press, Chattanooga. Available http://www.timesfreepress.com/news/2011/aug/04/river-temperature-forces-plant-to-50percent/. (5 August 2011).

Sovacool, B.K. 2009. Running on Empty: The Electricity-Water Nexus and the US Electric Utility Sector. Energy Law Journal 30 (11), 11-51.

Sovacool, B.K. and K.E. Sovacool. 2009. Preventing National Electricity-Water Crisis Areas in the United States. Columbia Journal of Environmental Law 34 (2), 333-393.

USDOE (United States Department of Energy). 2006. Energy Demands on Water Resources: Report to Congress on the Interdependency of Energy and Water. Washington DC.

USDOE/EIA (USDOE / Energy Information Agency). 2011. International Energy Outlook 2011. DOE/EIA-0484(2011).

USDOE/NETL (USDOE / National Energy Technology Laboratory). 2009a (revised). Water Requirements for Existing and Emerging Thermoelectric Plant Technologies. DOE/NETL-402/080108. 
USDOE/NETL. 2009b. Estimating Freshwater Needs to Meet Future Thermoelectric Generation Requirements. DOE/NETL-400/2009/1339.

USDOE/NETL. 2009c. Impact of Drought on US Steam Electric Power Plant Cooling Water Intakes and Related Water Resource Management Issues. DOE/NETL-2009/1364.

Van Vliet, M.T.H., J.R. Yearsley, F. Ludwig, S. Vögele, D.P. Lettenmaier and $\quad$ P. Kabat. 2012. Vulnerability of US and European electricity supply to climate change. Nature Climate Change 2, 676-681 (2012).

Viehmann, J. 2011. Risk premiums in the German day-ahead Electricity Market. Energy Policy 39(1), pp.386-394.

World Nuclear Association (WNA). March 2011 (updated). Nuclear Power Reactors. Available: http://www.world-nuclear.org/info/inf32.html. (25 July 2011). 
Figure 1. Final electricity demand in 2009

\section{(a) Germany}

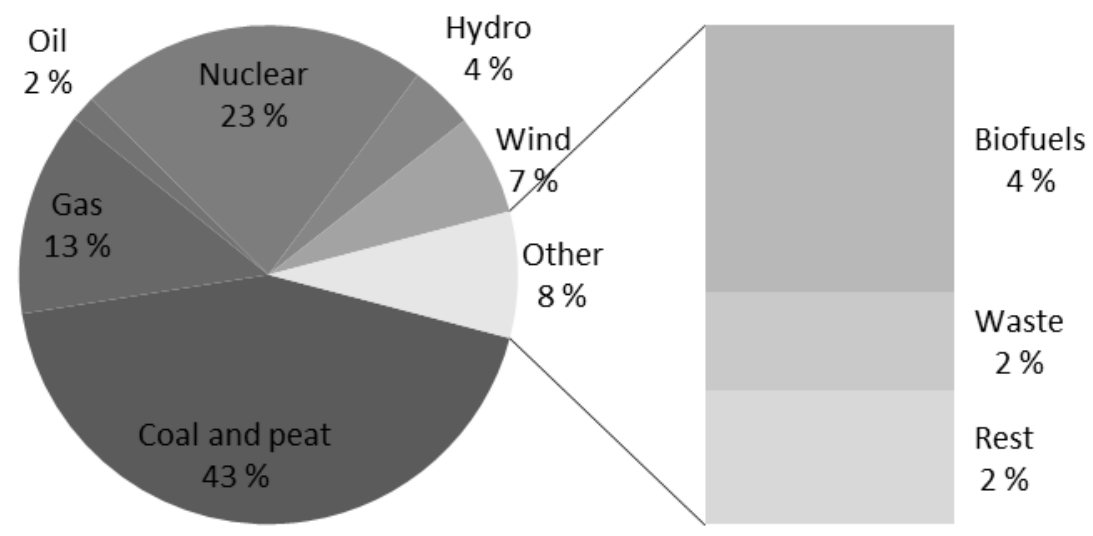

(b) OECD Total

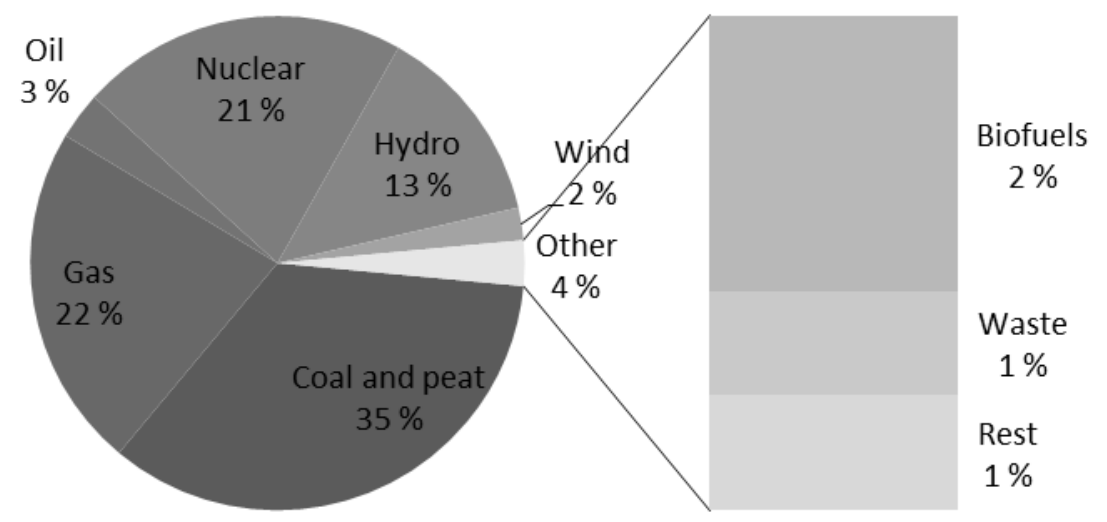

Source: International Energy Agency 
Figure 2. Water intake and cooling for a power plant

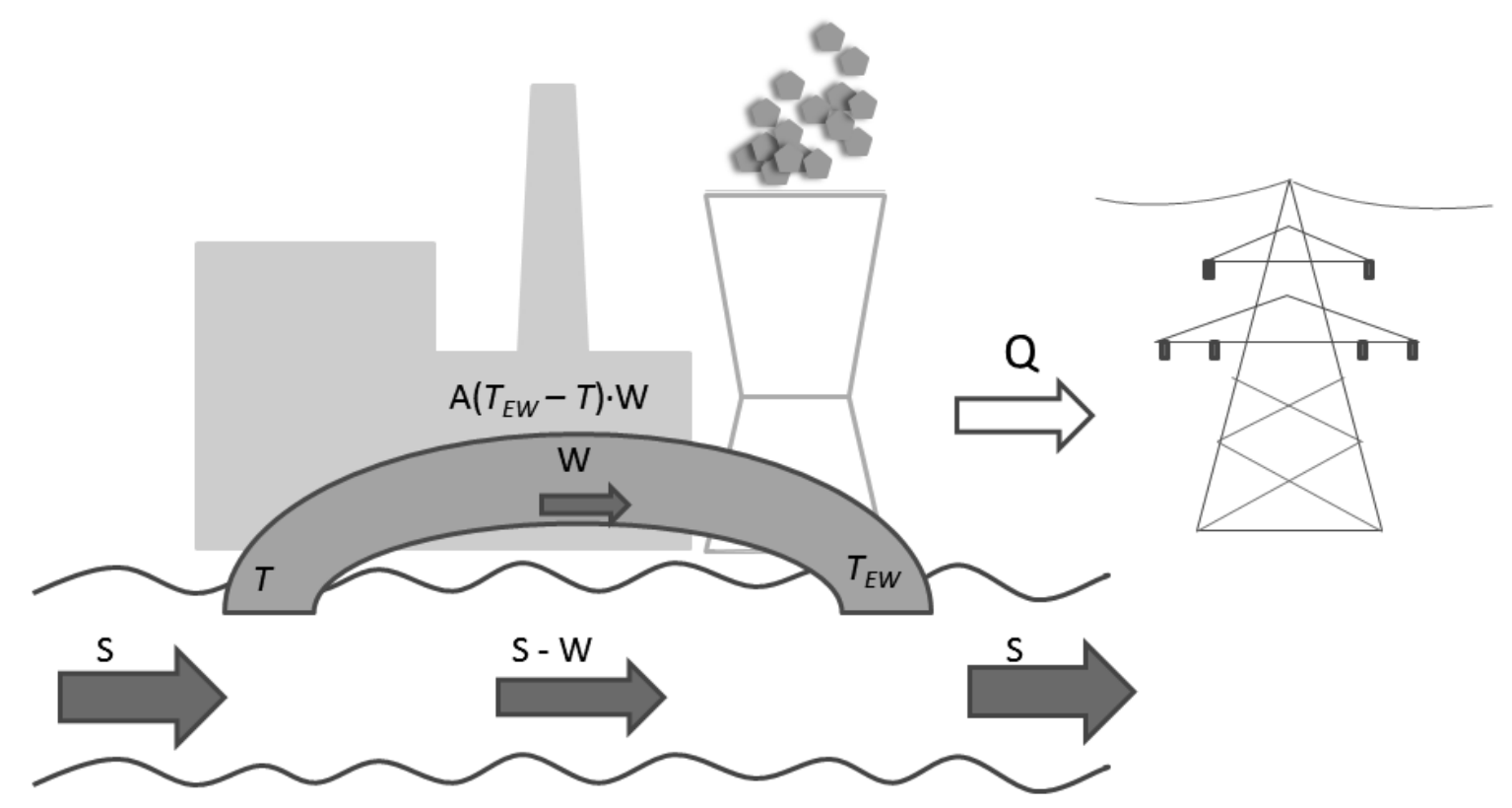


Figure 3. Air temperature in Germany (daily mean)

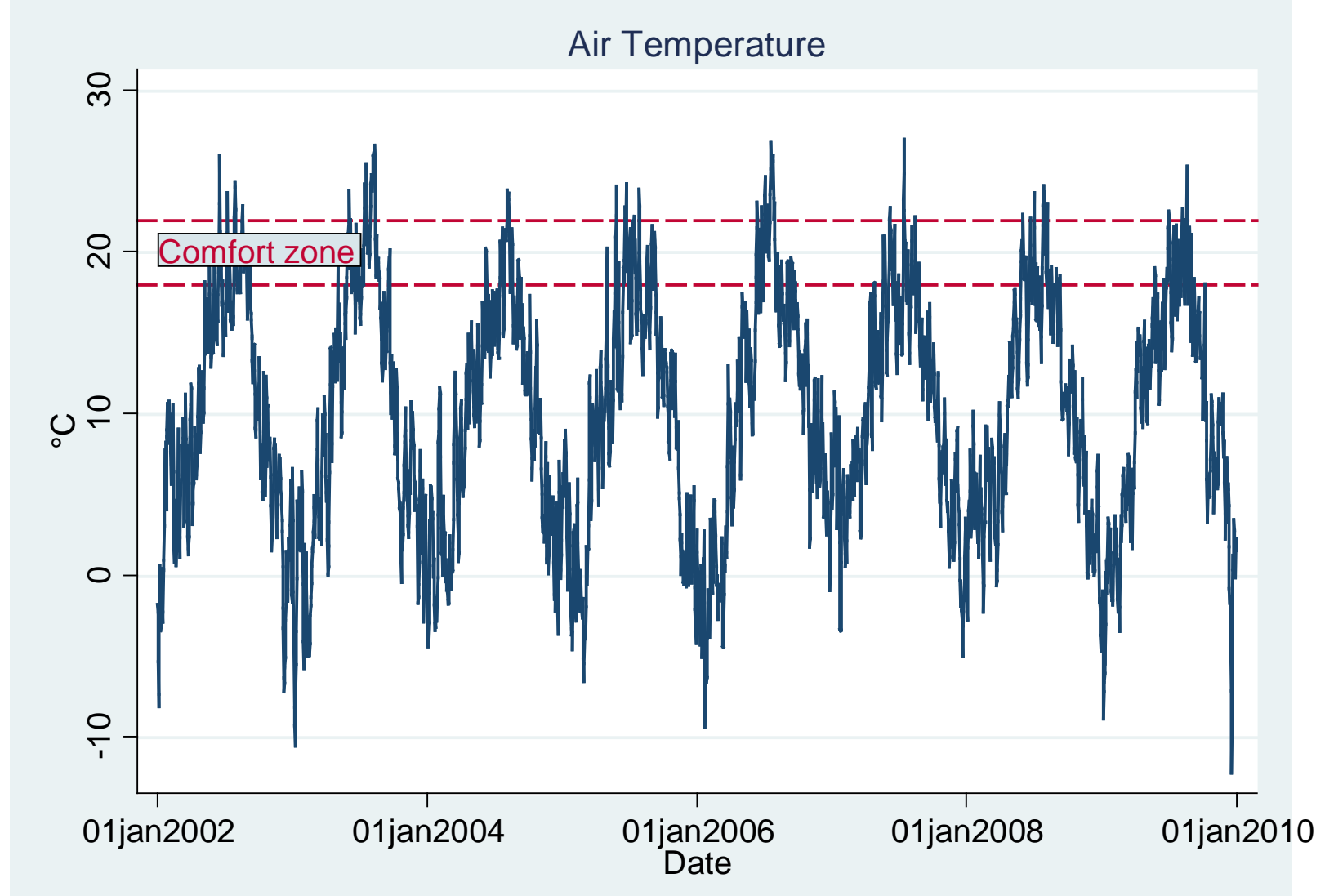


Figure 4. The effect of river temperatures on electricity price

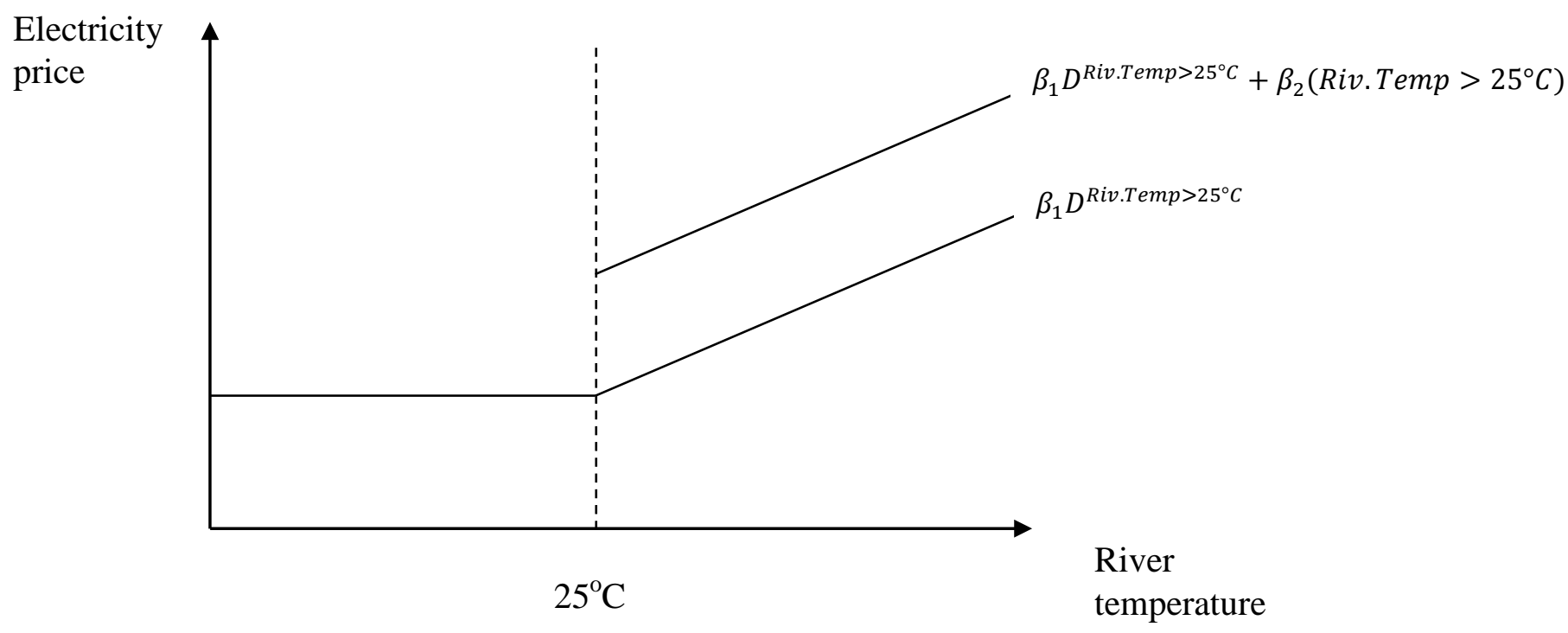


Table 1. Primary Models

\begin{tabular}{|c|c|c|c|}
\hline \multirow{2}{*}{\multicolumn{4}{|c|}{ Dep. Var. = Price (€/MWh) }} \\
\hline & & & \\
\hline \multicolumn{4}{|l|}{ COEFFICIENTS } \\
\hline Volume (1,000 MWh) & $\begin{array}{c}5.976^{* *} \\
(0.503)\end{array}$ & $\begin{array}{c}8.267 * * \\
(1.020)\end{array}$ & $\begin{array}{c}8.233 * * \\
(0.998)\end{array}$ \\
\hline \multicolumn{4}{|l|}{ Predetermined Variables } \\
\hline L1.Price & & $\begin{array}{l}0.624 * * \\
(0.0541)\end{array}$ & $\begin{array}{l}0.625 * * \\
(0.0537)\end{array}$ \\
\hline L7.Price & & $\begin{array}{c}0.138 * \\
(0.0533)\end{array}$ & $\begin{array}{l}0.141^{* *} \\
(0.0526)\end{array}$ \\
\hline L1.Volume & & $\begin{array}{c}-3.729 * * \\
(0.466)\end{array}$ & $\begin{array}{c}-3.697 * * \\
(0.451)\end{array}$ \\
\hline L7.Volume & & $\begin{array}{c}-2.280 * * \\
(0.372)\end{array}$ & $\begin{array}{c}-2.272^{* *} \\
(0.361)\end{array}$ \\
\hline \multicolumn{4}{|l|}{ River Levels (cm) } \\
\hline Single series & $\begin{array}{c}-1.025^{* *} \\
(0.234)\end{array}$ & $\begin{array}{c}-0.389 * * \\
(0.135)\end{array}$ & \\
\hline \multicolumn{4}{|l|}{ Splines (by percentiles) } \\
\hline "Low" (0-33\%) & & & $\begin{array}{l}-0.206 \\
(0.232)\end{array}$ \\
\hline "Medium” (33-67\%) & & & $\begin{array}{l}-0.148 \\
(0.303)\end{array}$ \\
\hline "High" (67-100\%) & & & $\begin{array}{c}-0.580 * * \\
(0.223)\end{array}$ \\
\hline \multicolumn{4}{|l|}{ River Temperature $\left({ }^{\circ} \mathrm{C}\right)$} \\
\hline $\mathrm{D}_{\text {Riv25 }}\left(1=\right.$ River Temp $\left.>25^{\circ} \mathrm{C}\right)$ & $\begin{array}{c}0.094 \\
(0.156)\end{array}$ & $\begin{array}{l}-0.0529 \\
(0.0751)\end{array}$ & $\begin{array}{c}-0.027 \\
(0.0744)\end{array}$ \\
\hline RivTemp - $25^{\circ} \mathrm{C}$, if $>25^{\circ} \mathrm{C}$ & $\begin{array}{l}0.277 * * \\
(0.0550)\end{array}$ & $\begin{array}{l}0.210 * * \\
(0.0286)\end{array}$ & $\begin{array}{l}0.218 * * \\
(0.0288)\end{array}$ \\
\hline Brent (90-day MA, €/bbl) & $\begin{array}{c}0.528 * * \\
(0.442)\end{array}$ & $\begin{array}{c}0.163 \\
(0.200)\end{array}$ & $\begin{array}{c}0.149 \\
(0.185)\end{array}$ \\
\hline \multicolumn{4}{|l|}{ TESTS (p-values) } \\
\hline Endogeneity test $^{\mathrm{a}}$ & 0.0000 & 0.0000 & 0.0000 \\
\hline Instrumental variable test $^{\mathrm{b}}$ & 0.0000 & 0.0000 & 0.0000 \\
\hline Overidentifying restrictions test ${ }^{\mathrm{C}}$ & 0.2012 & 0.0662 & 0.0671 \\
\hline \multicolumn{4}{|l|}{ Joint significance tests } \\
\hline Month Dummies & 0.0000 & 0.0000 & 0.0000 \\
\hline Year Dummies & 0.0000 & 0.0000 & 0.0000 \\
\hline$N$ & 2922 & 2915 & 2915 \\
\hline
\end{tabular}


Notes: All variables are entered in logarithmic form. Standard errors for the coefficients are reported in parentheses. For the tests, p-values are reported rather than test statistics. A constant term, year and month dummies are also included as regressors in the price equation. However, the estimated coefficients attached to these variables are not reported in the table. Heating degree days (HDD), cooling degree days $(C D D)$, and a Non-Working Day dummy are used as instruments in the first-stage regression.

${ }^{a}$ Durbin-Wu-Hausman test includes the saved residuals from the first-stage regression in the second stage of the 2SLS estimation. $\mathrm{H}_{0}$ : System is exogenous.

${ }^{b}$ Anderson's canonical correlations test of the rank condition of the (system of equations) matrix. $\mathrm{H}_{0}$ : System is unidentified and the instruments are not relevant.

${ }^{\mathrm{c}}$ The Hansen J statistic for overidentifying restrictions is computed using HAC estimators. $\mathrm{H}_{0}$ : Instruments are exogenous. 
Table 2. Individual River Levels

\begin{tabular}{|c|c|c|c|c|}
\hline & Elbe & Main & Neckar & Rhine \\
\hline \multicolumn{5}{|l|}{ Dep. Var. = Price (€/MWh) } \\
\hline \multicolumn{5}{|l|}{ COEFFICIENTS } \\
\hline Base Volume & $\begin{array}{l}8.099 * * \\
(1.004)\end{array}$ & $\begin{array}{l}8.256^{* *} \\
(1.020)\end{array}$ & $\begin{array}{l}8.081 * * \\
(0.982)\end{array}$ & $\begin{array}{l}8.277 * * \\
(1.029)\end{array}$ \\
\hline \multicolumn{5}{|l|}{ Predetermined Variables } \\
\hline L1.Base Price & $\begin{array}{l}0.644^{* *} \\
(0.0530)\end{array}$ & $\begin{array}{l}0.633 * * \\
(0.0532)\end{array}$ & $\begin{array}{l}0.623 * * \\
(0.0527)\end{array}$ & $\begin{array}{l}0.620 * * \\
(0.0553)\end{array}$ \\
\hline L7.Base Price & $\begin{array}{l}0.158^{*} \\
(0.0540)\end{array}$ & $\begin{array}{c}0.153^{* *} \\
(0.0530)\end{array}$ & $\begin{array}{c}0.168 * * \\
(0.0531)\end{array}$ & $\begin{array}{l}0.140^{* *} \\
(0.0537)\end{array}$ \\
\hline L1.Base Volume & $\begin{array}{l}-3.738 * * \\
(0.464)\end{array}$ & $\begin{array}{l}-3.757^{* *} \\
(0.460)\end{array}$ & $\begin{array}{l}-3.672 * * \\
(0.447)\end{array}$ & $\begin{array}{l}-3.749 * * \\
(0.472)\end{array}$ \\
\hline L7.Base Volume & $\begin{array}{l}-2.230 * * \\
(0.374)\end{array}$ & $\begin{array}{l}-2.330 * * \\
(0.368)\end{array}$ & $\begin{array}{l}-2.271^{* *} \\
(0.360)\end{array}$ & $\begin{array}{l}-2.284^{* *} \\
(0.379)\end{array}$ \\
\hline
\end{tabular}

River Levels (cm)

Single series

$\begin{array}{llll}-0.130 & -0.372 * & -0.511^{* *} & -0.217^{* *} \\ (0.0741) & (0.171) & (0.142) & (0.0740)\end{array}$

River Temperature $\left({ }^{\circ} \mathrm{C}\right)$

$\begin{array}{lllll}\mathrm{D}_{\text {Riv25 }}\left(1=\text { River Temp }>25^{\circ} \mathrm{C}\right) & -0.0246 & 0.00289 & 0.00373 & -0.0683 \\ & (0.0732) & (0.0739) & (0.0739) & (0.0752) \\ \text { River Temp, if }>25^{\circ} \mathrm{C} & 0.208^{* *} & 0.222^{* *} & 0.227^{* *} & 0.210^{* *} \\ & (0.0301) & (0.0282) & (0.0284) & (0.0280) \\ \text {-day MA }) & 0.131 & 0.113 & 0.0755 & 0.137 \\ & (0.194) & (0.189) & (0.191) & (0.205)\end{array}$

TESTS (p-values)

Endogeneity test $^{\mathrm{a}}$

$\begin{array}{llll}0.0000 & 0.0000 & 0.0000 & 0.0000\end{array}$

Instrumental variable test ${ }^{\mathrm{b}}$

$\begin{array}{llll}0.0000 & 0.0000 & 0.0000 & 0.0000\end{array}$

Overidentifying restrictions test ${ }^{c}$

$0.0716 \quad 0.0555$

$0.0613 \quad 0.0731$

Joint significance tests

\begin{tabular}{llllll} 
& Month Dummies & 0.0000 & 0.0000 & 0.0000 & 0.0000 \\
& Year Dummies & 0.0000 & 0.0000 & 0.0000 & 0.0000 \\
\hline$N$ & 2915 & 2915 & 2915 & 2915 \\
\hline
\end{tabular}

${ }^{*} p<0.05,{ }^{* *} p<0.01$

Notes: Based on Model (2) in Table 1. For each regression, the average river level series from Model (2) have been replaced with level data from an individual river. All other coefficients are excluded.

a b Please see Table 1 for interpretation 


\section{Appendix}

The effect of changes of river temperature, $T$, on optimal quantity, $Q^{*}$, and price, $p^{*}$

We start from our FOC

$$
p^{*}\left(1-\frac{1}{\varepsilon}\right)=\frac{\partial c\left(Q^{*}\right)}{\partial Q}+p_{w}(R L) \cdot \frac{1}{A\left(T_{E W}-T\right)}+\lambda \cdot \frac{1}{S \cdot A\left(T_{E W}-T\right)} \cdot\left(T_{E W}-T\right)
$$

and want to find the effect of a river-level temperature increase on the prices. Using standard comparative statics we define the problem as follows (e.g. chapter 8 of Dixit, 1976);

$$
\frac{d Q}{d T}=-\frac{\partial G(Q, T) / \partial T}{\partial G(Q, T) / \partial Q}
$$

where

$$
\begin{aligned}
G(Q, T) & =\frac{W}{S} T_{E W}+\frac{S-W}{S} T \\
& =\frac{W}{S}\left(T_{E W}-T\right)+1 \\
& =\frac{Q}{S \cdot A(.)}\left(T_{E W}-T\right)+1
\end{aligned}
$$

which is the LHS of the constraint $G(Q, T) \leq \bar{T}$. We have that

$$
\frac{\partial G(.)}{\partial Q}=\frac{T_{E W}-T}{S \cdot A(.)}>0
$$

and 


$$
\begin{aligned}
\frac{\partial G(.)}{\partial T} & =\frac{Q}{S}\left[\frac{A^{\prime}(.)\left(T_{E W}-T\right)-A(.)}{A(.)^{2}}\right]+1 \\
& =\frac{A(.) \cdot W}{S}\left[\frac{A^{\prime}(.)\left(T_{E W}-T\right)-A(.)}{A(.)^{2}}\right]+1 \\
& =\frac{1}{A(.)}\left\{\frac{W}{S}\left[A^{\prime}(.)\left(T_{E W}-T\right)-A(.)\right]+A(.)\right\} \\
& =\frac{1}{A(.)}\left\{\frac{S-W}{S} A(.)+A^{\prime}(.)\left(T_{E W}-T\right)\right\}>0
\end{aligned}
$$

as long $A^{\prime}()>$.0 (and $T_{E W}>T$ ). That means that $\frac{d Q}{d T}<0$. This is an inward shift of the supply curve. With given demand, and assuming that the supply curve is not completely flat, then the temperature will lead to increased prices. 